\title{
Roles of spacing and angle of slit-type barriers on velocity reduction of debris flows
}

\author{
Shin-Kyu Choi ${ }^{\text {i) }}$ and Tae-Hyuk Kwon ${ }^{\text {ii) }}$
}

\begin{abstract}
i) Graduate student, Dept. of Civil and Environmental Engineering, KAIST, 291 Daehak-ro, Daejeon 305701, KOREA. ii) Assistant Professor, Dept. of Civil and Environmental Engineering, KAIST, 291 Daehak-ro, Daejeon 305701, KOREA.
\end{abstract}

\begin{abstract}
Debris flows caused by heavy rainfall occur along long watersheds and travel at extremely rapid velocity. These debris flows can impact large areas and often cause economic and societal damages. For this reason, barriers against debris flows have been widely constructed. In particular, slit-type barriers are popularly used because of the minimum environmental disturbance. However, the performance of such slit-type barriers is not fully understood. This paper explores roles of spacing and angle of slit-type barriers on velocity reduction of debris flows. The scaled physical modeling experiments were performed to identify reduction of debris velocity and to assess the performance of debris flow barriers. The results indicate that the performance of barriers is heavily affected by spacing between slit-type barriers and angle of barriers from flow direction.
\end{abstract}

Keywords: debris flows, slit-type barriers, physical model, velocity, spacing, angle

\section{INTRODUCTION}

A debris flow is a fast flow phenomenon of a soilwater mass that occurs when a collapsed soil mass from landslides meets water in a steep channel during heavy rains. This phenomenon shows a fast moving fluid induced by gravity as a form of continuous fluid and has a great fluidity because the space between soil and stone is filled with water or slurry (Calligaris and Zini, 2012). A debris flow consists of various mixtures of small size material (silt and clay) and relatively big size material (boulders and woods) (Iverson, 1997). This composition is determined by the characteristics of the basin near the beginning of the debris flow and near the flow channel. Boulders and woods with big momentum which located at the tip of the flows scour the sediment in the floor of channel. According to this mechanism, the volume of debris flows is increased as it flows down. In addition, some part of debris flows are deposited in the middle of flow channel and lateral levees are made on the both sides of channel. (Iverson, 2003).

Debris flows are considered as one of the potential geohazards that can damage nearby houses, buildings and infrastructures in the city as the debris flows spread over a wide area (Hübl et al., 2009). As a result, installing debris barriers that can decrease the velocity of debris flows is one of the widely used methods to prevent the damages caused by debris flows. There are two kinds of debris barriers: one is a closed-type barrier (Fig. 1), and another is an opentype barrier (Fig. 2). Especially, the open-type barrier can reduce the velocity of the debris flows and trap the boulders and drift-woods while minimizing environmental disturbance. Such open-type barriers become widely chosen because of these advantages, however, the mechanisms or performance of the open-type barriers are not fully understood.

In this study, the mechanisms and performance of slit-type barriers, one kind of the various open-type barriers, were explored. Effects of the spacing between slit-type barriers and the angle of barriers on the velocity of debris flow were investigated via small-scale laboratory experiments. Debris flows during the laboratory experiments were captured by using high-speed cameras, and the captured images were analyzed using a particle tracking velocimetry (PTV) method (Thielicke and Stamhuis, 2010) to extract the velocities of the debris flows before and after passing the slit-type barriers. The changes in velocity of debris flows were used as an indicator to analyze the influence of slit-type barrier arrangement on debris flow patterns.

\section{EXPERIMENTAL PROGRAM}

\subsection{Experimental setup and procedure}

A rectangular-shaped acrylic flow channel was designed to analyze the effect of arrangement of slittype barriers on debris flow patterns, as shown in Fig. 3. The flow channel is $0.40 \mathrm{~m}$ wide, $0.3 \mathrm{~m}$ high, $1.4 \mathrm{~m}$ long, and the slope of the channel can be readily controlled from $0^{\circ}$ to $50^{\circ}$. 


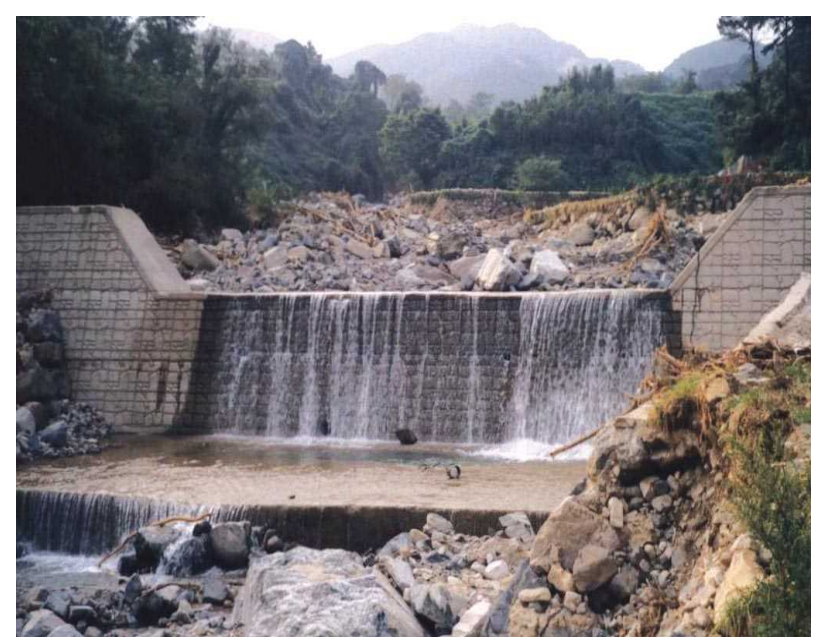

Fig. 1. A closed-type barrier after a debris flow event in Korea (Korea Forest Service, 2009).

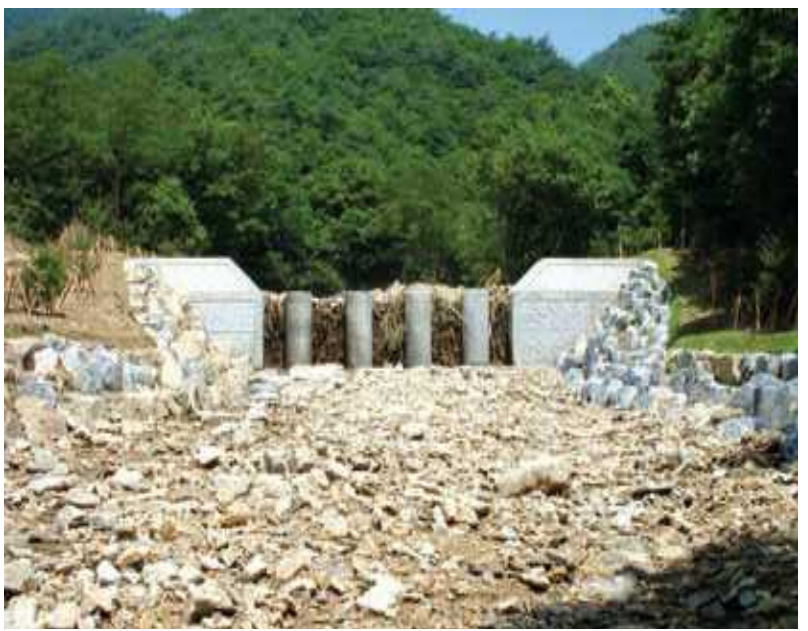

Fig. 2. An open-type barrier after a debris flow event in Korea (Korea Forest Service, 2009).

Debris flows were filmed or captured with two high-speed cameras (UI-3240LE, UI-3240ML; IDS Corp.) installed at the upstream and downstream of the slit-type barriers. The images were captured at a rate of 123 frames per second and with a resolution of $960 \times 480$ pixels. The captured images were used to analyze the velocities and patterns of debris flows before and after passing the slit-type barriers, or at the upstream (Section A in Fig. 3) and downstream areas (Section B), respectively.

A soil-water mass for generating a debris flow was prepared by mixing $2 \mathrm{~kg}$ water and $0.5 \mathrm{~kg}$ Joomunjin standard sand. The prepared soil-water mixture was placed in the box at the most upper part of the channel. The box had a gate, as shown in Fig. 3. By opening the gate, a debris flow was generated. While the slopes for debris flow has been generally reported to be steeper than $10^{\circ}$ (Gregoretti, 2000), the slope of our channel was fixed at $13^{\circ}$ over the course of the experiments.

\subsection{Arrangement of slit-type barriers}

We chose a slit-type barrier composed of a group of rectangular walls for this study. A rectangular wall was simulated by a acrylic plate that was $50 \mathrm{~mm}$ wide, $60 \mathrm{~mm}$ high, and $13 \mathrm{~mm}$ thick. A group of these acrylic plates represents a slit-type barrier against debris flows. These rectangular walls were placed in the middle of the flow channel (Fig. 3). The wall was designed to be high enough to avoid overflows during the experiments.

Fig. 4 shows ten different cases of the wall arrangements. Case 0 was conducted without walls as a reference case. Since the widths of the channel and a wall were $40 \mathrm{~cm}$ and $5 \mathrm{~cm}$, respectively, eight walls aligned horizontally can completely block the channel. In order to identify the effect of spacing, one of the walls at the center out of eight walls was removed (Case 1; 7 walls with a center window; Fig. 4a). In Case 2, the seven walls were separated equally (7 walls; Fig. 4b). Case 3 and Case 4 were arranged in the same way as Case 1 and Case 2 with six walls (Figs. 4c and 4d). In Cases 5, 6 and 7, seven walls were placed at an angle of $60^{\circ}, 45^{\circ}$ and $30^{\circ}$, respectively, with respect to the flow direction (see Figs. 4e, 4f, and 4g). Cases 5, 6, and 7 were designed to investigate the effect of angle. Lastly, two layers consisting of $45^{\circ}$-tilted walls were arranged with various distances between the center and center of walls (see Figs. 4h, 4i, and 4j). The distances between two layers were $5 \mathrm{~cm}$ (Case 8), $7 \mathrm{~cm}$ (Case 9), and 9 $\mathrm{cm}$ (Case 10). Table 1 summarizes all cases for wall arrangement.

\section{RESULS AND ANALYSES}

\subsection{Velocity analysis}

The velocity changes of debris flows due to various arrangements of slit-type barriers were measured to investigate the effect of spacing between barriers and angle of barriers with respect to flow direction. Time-lapsed images captured by high speed cameras were used to measure the velocity by using the PTV (particle tracking velocimetry) code.

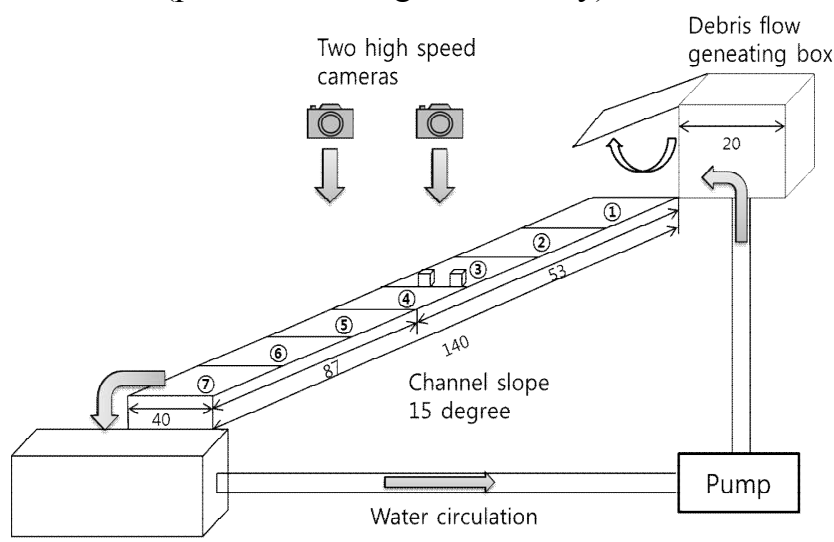

Fig. 3. A schematic drawing of the experimental setup (not to scale). The dimension is in centimeters. 


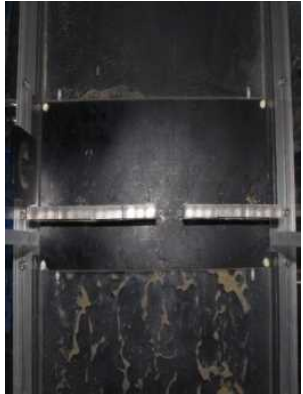

(a)

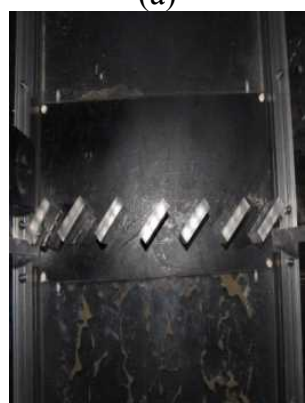

(f)

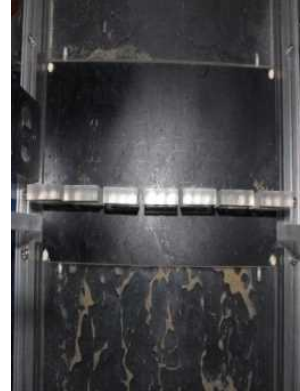

(b)

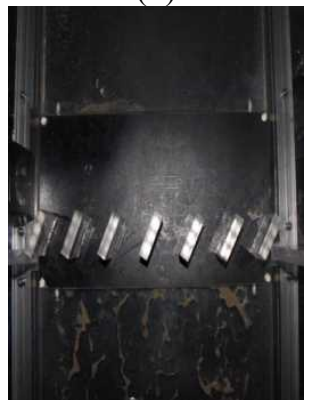

(g)

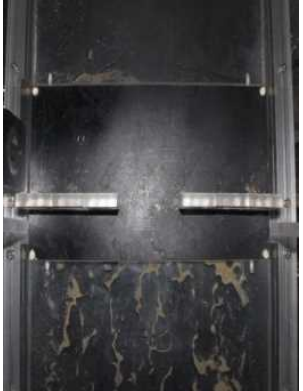

(c)

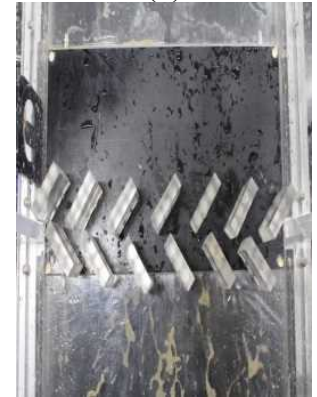

(h)

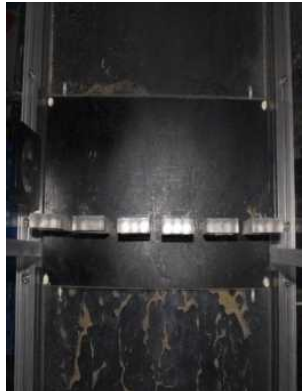

(d)

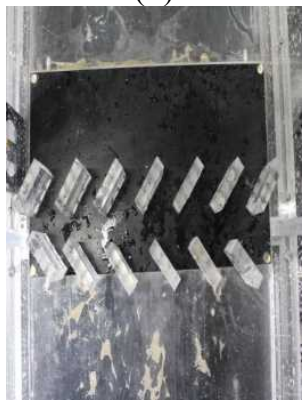

(i)

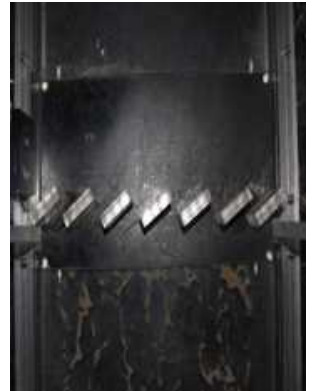

(e)

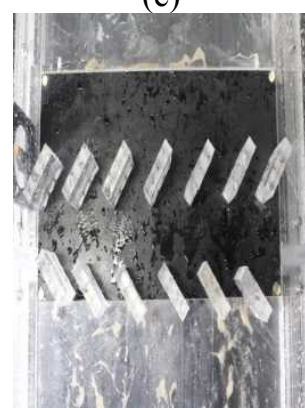

(j)

Fig. 4. Arrangements of slit-type barriers.

Table 1. Test conditions for the barrier arrangement

\begin{tabular}{lccccc}
\hline & $\begin{array}{c}\text { Number } \\
\text { of barriers }\end{array}$ & $\begin{array}{c}\text { Number } \\
\text { of slits }\end{array}$ & $\sum \mathrm{b} / \mathrm{B}$ & $\begin{array}{c}\text { Angle of } \\
\text { barriers }\left({ }^{\circ}\right)\end{array}$ & $\begin{array}{c}\text { Number } \\
\text { of layers }\end{array}$ \\
\hline Case 1 & 7 & 1 & 0.875 & 90 & 1 \\
\hline Case 2 & 7 & 6 & 0.875 & 90 & 1 \\
\hline Case 3 & 6 & 1 & 0.750 & 90 & 1 \\
\hline Case 4 & 6 & 5 & 0.750 & 90 & 1 \\
\hline Case 5 & 7 & 6 & 0.872 & 60 & 1 \\
\hline Case 6 & 7 & 6 & 0.780 & 45 & 1 \\
\hline Case 7 & 7 & 6 & 0.635 & 30 & 1 \\
\hline Case 8 & 13 & 6 & 0.780 & 45 & 2 \\
\hline Case 9 & 13 & 6 & 0.780 & 45 & 2 \\
\hline Case 10 & 13 & 6 & 0.780 & 45 & 2 \\
\hline
\end{tabular}

Table 2 shows the velocities and the velocity reduction rate of debris flows. The velocity at downstream for Case 0 was estimated as $1.2 \mathrm{~m} / \mathrm{s}$, and this was used as the reference velocity to calculate the reduction rate.

\subsection{Effect of barrier spacing}

The result of Case 1 shows the velocity was reduced from $1.2 \mathrm{~m} / \mathrm{s}$ to $0.78 \mathrm{~m} / \mathrm{s}$ by energy dissipation due to collisions with the barriers. However, the center part of a debris flow was not slowed down due to the passage through the center window. Reduction rate in Case 2 was $50 \%$, which was larger than that of Case 1 . It indicates that the case with at regular intervals (Case 2) performs better than the case with a center window (Case 1) for the same total length of slits because of more collisions of soils to the barriers. Although the velocities of Cases 3 and 4 were reduced than Case 0 (without walls), the reduction rates were smaller than those of Cases 1 and 2. This demonstrates that more debris passed without any interruptions because of larger spacing than Cases 1 and 2.

\subsection{Effect of barrier angle}

Cases 5, 6 and 7, as compared to Case 1, were designed to explore the performance of the tilted barriers. The results revealed that the greater angle with respect to the flow direction resulted in the larger velocity reduction rate because the spacing length relative to the channel width was minimized. When the angle of barriers from flow direction was $30^{\circ}$, the channel was almost opened, as a result, the reduction rate was close to $0 \%$. As the angle of barriers increased, the amount of trapped materials also increased. It implies that the barriers performed properly when the angle of barriers was higher than $30^{\circ}$.

Apparently, the reduction rate was the greatest when barriers were installed in the perpendicular to the flowing direction (i.e., $90^{\circ}$ ). In this case, the collision impact would be the greatest, which can lead to overturning of the barriers. Therefore, the barriers would be inevitably designed to be thick enough to withstand the impact of debris flows. However, by installing the tilted barriers, the more economic design can be developed. Therefore, it is necessary to determine the effective angle of barriers. For instance, two layers of barriers with a low angle may perform better than one layer of barriers with a high angle. By installing several layers with low angle of barriers, the barriers could prevent the debris flows effectively.

\subsection{Effect of distance between layers}

To analyze the effect of the distance between layers, Cases 8, 9, and 10 were investigated, where two layers of thirteen barriers ( 7 and 6 barriers at each layer; see Figs. 4h, 4i, and $4 \mathrm{j}$ ) with $45^{\circ}$ were placed. The reduction rates of $39 \%, 33 \%$, and $24 \%$ were found for 5 $\mathrm{cm}, 7 \mathrm{~cm}$, and $9 \mathrm{~cm}$ intervals, respectively. 
Table 2. Test results

\begin{tabular}{|c|c|c|c|}
\hline & \multicolumn{2}{|c|}{ Velocity of debris flows $(\mathrm{m} / \mathrm{s})$} & \multirow{2}{*}{$\begin{array}{c}\text { Reduction rate } \\
(\%)\end{array}$} \\
\hline & Upstream & Downstream & \\
\hline Case 0 & 1.10 & 1.2 & - \\
\hline Case 1 & 1.10 & 0.78 & 35 \\
\hline Case 2 & 1.10 & 0.60 & 50 \\
\hline Case 3 & 1.15 & 0.98 & 18 \\
\hline Case 4 & 1.15 & 1.00 & 17 \\
\hline Case 5 & 1.10 & 0.77 & 36 \\
\hline Case 6 & 1.10 & 0.88 & 27 \\
\hline Case 7 & 1.10 & 1.20 & 0 \\
\hline Case 8 & 1.00 & 0.73 & 39 \\
\hline Case 9 & 1.00 & 0.80 & 33 \\
\hline Case 10 & 1.10 & 0.91 & 24 \\
\hline
\end{tabular}

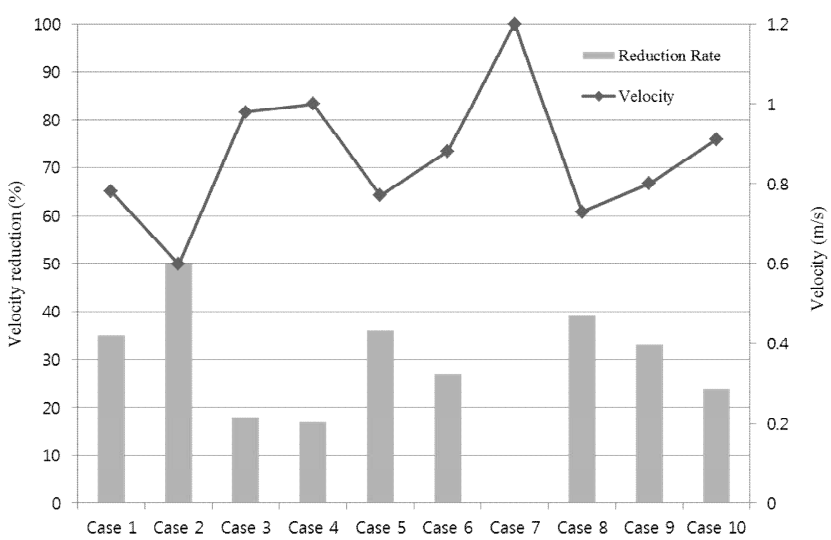

Fig. 5. The velocities measured at the downstream and the rates of velocity reduction.

The velocity reduction in Case 10 was even smaller than Case 6 that has only one layer with the same angle. It means that the distance between layers was too big for the second layer to reduce the velocity effectively. Both the amount of captured debris and the velocity reduction rate increased as the spacing between layers decreased. Therefore, distance between layers was found to affect the performance of the barrier.

\section{CONCLUDING REMARKS}

This study has attempted to identify the performance of slit-type barriers against debris flows. Various parameters, including the spacing between slittype barriers, the angle of barriers, and the spacing between layers, were investigated via scaled laboratory experiments. Main findings are as follows.

- The rate of velocity reduction of debris increased with a decrease in the spacing between barriers .

- The rate of velocity reduction of debris and the amount of trapped soils increased with an increase in the angle of walls with respect to the flow direction. The reduction rate was the most when the barriers were installed perpendicular to the flow direction $\left(90^{\circ}\right)$. When the angle of barriers was lower than $30^{\circ}$, the wall showed insignificant effect on velocity reduction.
- The amount of trapped debris and the velocity reduction rate increased with a decrease in the distance between layers.

While there are many parameters affecting the performance of slit-type barriers, incorporation of proper scaling law is required prior to further extend the results obtained in this study for optimal design of barriers.

\section{ACKNOWLEDGEMENTS}

This research was supported by a grant (13SCIPS04) from Smart Civil Infrastructure Research Program funded by Ministry of Land, Infrastructure and Transport (MOLIT) of Korea government and Korea Agency for Infrastructure Technology Advancement (KAIA).

\section{REFERENCES}

1) Calligaris, C., and Zini, L. (2012). "Debris flow phenomena: a short overview", Earth Sciences. INTECH, Croatia, pp. 7190.

2) Gregoretti, C. (2000). "The initiation of debris flow at high slopes: experimental results", Journal of Hydraulic Research, Vol. 38, pp. 83-88.

3) Hübl, J., Suda, J., Proske, D., Kaitna, R., and Scheidl, C. (2009). "Debris flow impact estimation", In Eleventh international symposium on water management and hydraulic Engineering, Vol. 1, pp. 137-148.

4) Iverson, R. M. (1997). "The physics of debris flows", Reviews of geophysics, Vol. 35, pp. 245-296.

5) Iverson, R. M. (2003). "The debris-flow rheology myth", Debris-flow hazards mitigation: mechanics, prediction, and assessment, pp. 303-314.

6) Korea Forest Service. (2009) "Erosion control works", Korea Forest Service.

7) Thielicke, W., and Stamhuis, E. J. (2010). Pivlab-timeresolved digital particle image velocimetry tool for matlab Published under the BSD license, programmed with MATLAB. http://PIVlab.blogspot.com. 